\title{
DESIGN OF COCKPIT DISPLAYS TO EXPLICITLY SUPPORT FLIGHTCREW INTERVENTION TASKS
}

\author{
Lance Sherry, George Mason University, Fairfax, Virginia. \\ Robert Mauro, Decision Research, Eugene, Oregon.
}

\begin{abstract}
In a class of accidents, known as Controlled Flight into Stall (CFIS), a structurally, mechanically, and electronically sound aircraft decelerated through the minimum safe operating speed $\left(1.3 \mathrm{~V}_{\text {Stall }}\right)$ to the stick-shaker stall speed. These accidents followed a pattern in which a triggering event (e.g., sensor failure, flight crew entry) resulted in an automation mode change, which led to an inappropriate flight control command, which in turn resulted in a trajectory that violated the speed envelope. In all of these cases, the flight crew, who are required to "mind the gap" between the $10^{-5}$ automation design standard and the $10^{-9}$ operational hazard reliability standard, were not able to intervene in a timely manner. To address this phenomenon, researchers have proposed "low speed alerting" solutions, but this alerting takes place as the speed deviation occurs. What would it take to detect the speed deviation scenario before it occurs?
\end{abstract}

An analysis of the accidents, described in this paper, identified a subcategory of CFIS scenarios in which the automation was no longer actively controlling to the airspeed target. This situation was caused by: (1) the automation no longer being coupled to the control surfaces or (2) the automation being coupled but transitioning to a mode that intentionally does not control to the airspeed target (e.g. Flare, or dormant). The analysis shows that flight deck displays do not provide the explicit information that would enable the flight crew to detect and recognize the inactive speed control or the two contributing factors. The implications of these results for design and certification of flight deck automation are discussed.

\section{Introduction}

In several recent accidents and incidents a structurally, mechanically, and electronically sound commercial airliner decelerated through the minimum safe operating speed $\left(1.3 \mathrm{~V}_{\text {Stall }}\right)$ to the stickshaker stall speed. These accidents, known as Controlled Flight into Stall (CFIS), followed a pattern in which a triggering event (e.g., sensor failure, flight crew entry) resulted in a mode change or change in automation engagement status, that led to an inappropriate command, that in turn resulted in the speed envelope violation [1].

In each of these accidents, the flight crew was not able to intervene in a timely manner. In all of these cases, the aircraft trajectory (e.g., deceleration) associated with the inappropriate automation commands could not be detected or recognized as it was masked by an appropriate deceleration trajectory leading up to the speed envelope violation.

Further, the cues identifying the triggering events and their effect on automation modes and engagement status did not lead to detection, recognition, or diagnosis as they were hidden from the flight crew by the absence of explicit annunciation. The mode labels were overloaded (i.e. same label has two different meanings) or the displayed data could not be interpreted without applying memorized rules.

Researchers have been developing concepts to improve the detection, recognition, and diagnosis of this speed deviation. For example, concepts to improve the salience of the low speed condition [2], provide additional displays to anticipate the low speed condition [3] and manage aircraft energy [4], [5] have been proposed,

The effects of the triggering events on the automation (i.e. changes in targets and modes) provide an opportunity to detect, recognize and diagnose the CFIS scenario prior to the occurrence of the speed deviation.

This paper describes an analysis of CFIS scenarios and the associated Human Computer Interaction (HCI) for detection, recognition and 
diagnosis based on the changes in modes and targets. The main results of the analysis are as follows:

- For a subset of the CFIS accidents, the accident scenario was the result of an automation mode change in which airspeed was no longer actively being controlled by the automation.

- There were two scenarios resulting in absent speed control: (1) the automation was no longer coupled to the engine controls, and (2) the automation was coupled to the engine controls, but it selected a control strategy that did not actively control airspeed.

- In both cases, flight crew intervention was not explicitly supported by the flight deck. Instead, the flight crew needed to rely upon memorized rules to interpret the available data and devise an intervention.

- When the automation was no longer coupled to the engine controls, the mode selection annunciated was not relevant.

- When the automation was coupled to the engine controls, there were cases in which the annunciation of the mode was ambiguous about whether airspeed was actively controlled.

These results highlight the design of the flight deck system, which requires the flight crew to monitor the aircraft automation to intervene should the automation command an inappropriate trajectory. In this way, flight crews are required to ensure a $10^{-9}$ operational reliability standard by monitoring equipment that is designed and certified to a $10^{-5}$ reliability standard. To enable the flight crew to "mind the gap" between these standards, an explicit, salient, and unambiguous user-interface that supports this intervention task must be part of the flight deck design. This paper describes the requirements for an integrated airspeed target display on the Primary Flight Display (PFD) to explicitly annunciate the absence of active airspeed control.

These results also highlight the contributing roles of the automation architecture (i.e. engagement status), ambiguous labeling (e.g. overloaded labels), disparate data displays, and the need for memorized rules. Any solution to this phenomena must address all of these issues.

Further, these results highlight the need to assess the changes in the role of the flight crew monitoring the automation, when new automation functionality that must be monitored to the $10^{-9}$ standard is introduced. Without careful consideration, the flight crew may be required to perform tasks, such as intervention tasks, that are not supported directly by the existing flight deck displays.

Finally, safety analyses (e.g. Fault Tree Analyses (FTA) and Failure Mode Effects Analysis (FMEA)) must explicitly address conditions related to situations when airspeed is intentionally not actively controlled. These situations are not always failure conditions.

This paper is organized as follows: the next section provides a model of flight deck operations and the roles of modes, targets, and automation engagement status. The following section describes the CFIS accidents and identifies categories of accident scenarios based on the flight deck model. The next section analyzes the HCI to perform the intervention task. The requirements for explicit annunciation of the intervention task are described along with an example of a proposed integrated target display. The implications on design and certification are discussed in the conclusions.

\section{A Model of Flight Deck Operations}

A model of flight deck operations is described along with a definition of terms to serve as the basis for the analysis.

The flight deck of a modern airliner, composed of the flight crew and the automation, is the "command and control" system for conduct of the flight (Figure 1).

The flight is executed according to a "flight plan" filed with Air Traffic Control (ATC). The flight plan is composed of a sequence of navigation procedures (e.g. Departure, Enroute, Standard Arrival, and Approach) that define the constraints of the desired four dimensional flight trajectory of the aircraft. A feasible flight plan reflects the performance constraints of the aircraft as well as the constraints imposed by regulatory procedures.

The flight, however, is conducted in a dynamic environment and will not be conducted exactly as described in the flight plan. The flight deck system is required to detect, recognize and adapt to changes in 


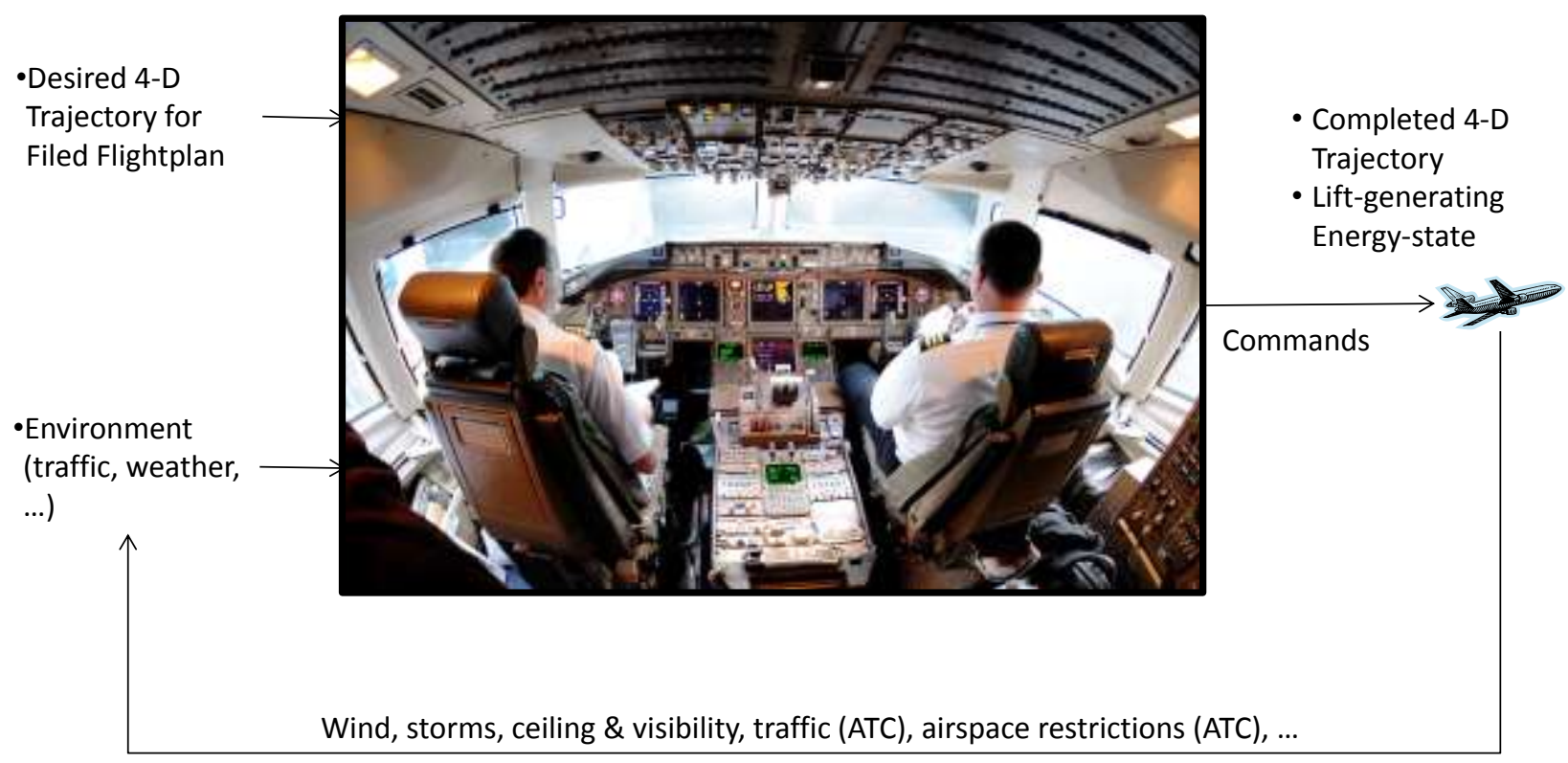

\section{FIGURE 1: The Flight Deck is the "Command And Control" System for the Conduct of a Revenue Service Flight.}

the environment including changes in traffic, weather, and airline network considerations. In particular, the flight deck system is designed to protect against hazards to achieve a target level of safety of $10^{-9}$. Examples of hazards include aircraft structural limits, energy-state (i.e. low speed stall), vehicle stability/loss-of-control, traffic collision, and terrain collision.

\section{Flight Deck Tasks}

The flight deck system is responsible for the execution of the flight plan in a dynamic and uncertain environment. As a consequence, the flight deck responsibilities can be organized into three categories: (1) coordinating flight plan progress, (2) managing expected (but unplanned) flight plan deviation events, and (3) managing unexpected flight plan deviation events.

(1) Coordinating flight plan progress: To ensure safe separation of flights and efficient flow of air traffic, ATC will "block airspace" (i.e. reserve the airspace) and then "clear" the aircraft to proceed along the next segment of the flight plan. These clearances provide permission for the aircraft to progress along the flight plan. The navigation procedures and each segment of the flight plans are explicitly designed for a sequence of targets and modes that yield a comfortable trajectory with smooth energy-state transitions.

(2) Managing expected (but unplanned) flight plan deviation events: Because the flight is conducted in a dynamic and uncertain environment, the flight plan cannot be flown strictly as filed. The flight deck system monitors the environment of the flight and intervenes when the procedure specified in the flight plan cannot be performed. Although these events are expected, and part of the SOPs, they are not included in the flight plan.

Examples of expected, but unplanned events include:

- Traffic that requires the flight to fly a holding pattern or to fly ATC vectors (e.g. s-turns, or speed changes)

- Weather (e.g. a storm cell) that requires the flight to deviate from the flight plan path (e.g. offset the lateral path, fly direct to an alternate fix, step-climb)

(3) Managing unexpected flight plan deviation events: Due to the complex nature of the environment in which the flight deck system 
operates, there are a myriad of rare events that require a deviation from the flight plan. One of the main classes of these events is an Automation Surprise in which the flight deck automation autonomously selects targets and/or modes that command a trajectory not commensurate with the flight plan. Events leading to automation surprises include inaccurate flight deck input information (e.g. from inaccurate sensor data or erroneous flight crew entries in support of ATC instructions).

\section{Control Strategies (i.e. Modes) and Targets}

A procedure is generally composed of a sequence of maneuvers (or trajectory segments) that require different energy-states. The energy states are achieved by a combination of targets (i.e. airspeed, altitude, rate-of-climb/descent, and course/heading) and control strategies, also known as "modes" (i.e. using elevator or thrust to control speed or altitude, and aileron/rudder to control heading). The flight deck determines the trajectory of the aircraft by generating the appropriate sequence of targets and modes, and by computing the associated pitch, thrust, and roll commands.

Unlike the lateral trajectory that has a single parameter to control (i.e. roll), the vertical trajectory requires the coordination of both pitch and thrust. To maintain a safe energy state the trajectory is restricted by the transition of energy state during each maneuver and the performance limits of the aircraft. In particular, managing expected (but unplanned) flight plan deviation events and managing unexpected flight plan events can require rapid transitions in energy states that reduce safety margins [6].

There are several maneuvers that are performed in which airspeed is the indirect outcome of control to a flight path using a fixed thrust setting. When the flight path is computed correctly, taking into account the thrust setting, the airspeed will achieve the correct value. However, if the flight path is not consistent with the performance of the aircraft (e.g. too steep or too shallow), the desired airspeed will not be achieved.

The choice of control strategies and targets is a complex decision-making activity. It requires consideration of a large number of inputs including actual aircraft state parameters (e.g. barometric altitude, calibrated airspeed, etc.), flight plan parameters (e.g. active leg altitude, speed, time constraints), traffic data, and terrain data.

\section{Roles and Responsibilities of Flight Deck Agents: Flight Crew and Automation}

The flight deck is composed of two agents: the flight crew and the automation. The flight deck automation extends the capabilities of human operators by performing fatiguing control tasks to a high degree of accuracy (e.g. stability augmentation and trajectory control), by rapidly performing complex calculations for predicting the future trajectory (e.g. fuel burn), and by performing complex optimizations (e.g. step-climb points, Econ speed).

The functionality of the automation has grown organically from (i) stability augmentation for stick and throttle inputs, to (ii) trajectory control from targets and mode selections, to (iii) optimum trajectory control from a flight plan. The userinterfaces for flight deck automation are summarized in Figure 2. The flight plan can be "programmed" by the flight crew via the Multi-function Control Display (MCDU) into the Flight Management Computer (FMC). Targets and modes can be selected directly by the flight crew on the Mode Control Panel (MCP), or the aircraft trajectory can be controlled directly via the stick and throttle.

The flight crew coordinates progress along the flight plan by transferring ATC flight plan clearances via the MCDU and the MCP. Expected but unplanned events are managed primarily by flight crew entries via the MCP (e.g. deviations around traffic) and, in some cases, by altering the flight plan using the MCDU (e.g. Holding Pattern, lateral path offsets, expedite climb). Unexpected events are managed by stick and throttle and the MCP. This is particularly the case when the flight crew is uncertain of the state and intentions of the automation.

In the event of an expected but unplanned event, or an unexpected event, the flight crew must recognize the situation through a combination of direct observation, communication with ATC, and/or information obtained from the automation user- 
interface. It is possible that due to the organic growth of the automation, the user-interface may not be designed to support detecting, recognizing and diagnosing many unexpected events.

\section{Automation Configuration}

Depending on the task (i.e. coordinating flight plan progress, managing expected/unplanned events, or managing unexpected events), the flight crew must configure the automation to "couple" the correct automation component to the control surfaces and engine.

The automation is designed with four "switches" to configure the automation (Figure 2). The Autopilot $(\mathrm{A} / \mathrm{P})$ and Autothrottle (A/T) switches determine whether manual commands (from stick and throttles) are commanding the aircraft trajectory or whether the commands are from the automation (i.e. FMC/Autopilot Mode Logic). The VNAV and LNAV switches determine whether the targets and control strategies are flight crew selected (on the MCP) or from the flight plan programmed into the FMC.

When the flight is progressing along the flight plan programmed into the FMC, the VNAV and LNAV switches are closed as are the A/P and A/T switches. This allows the automation to set the targets and modes to command the flight trajectory. VNAV, LNAV, the $\mathrm{A} / \mathrm{P}$ and $\mathrm{A} / \mathrm{T}$ are said to be "engaged."

If the flight plan can be amended to perform an expected but unplanned procedure, the flight crew

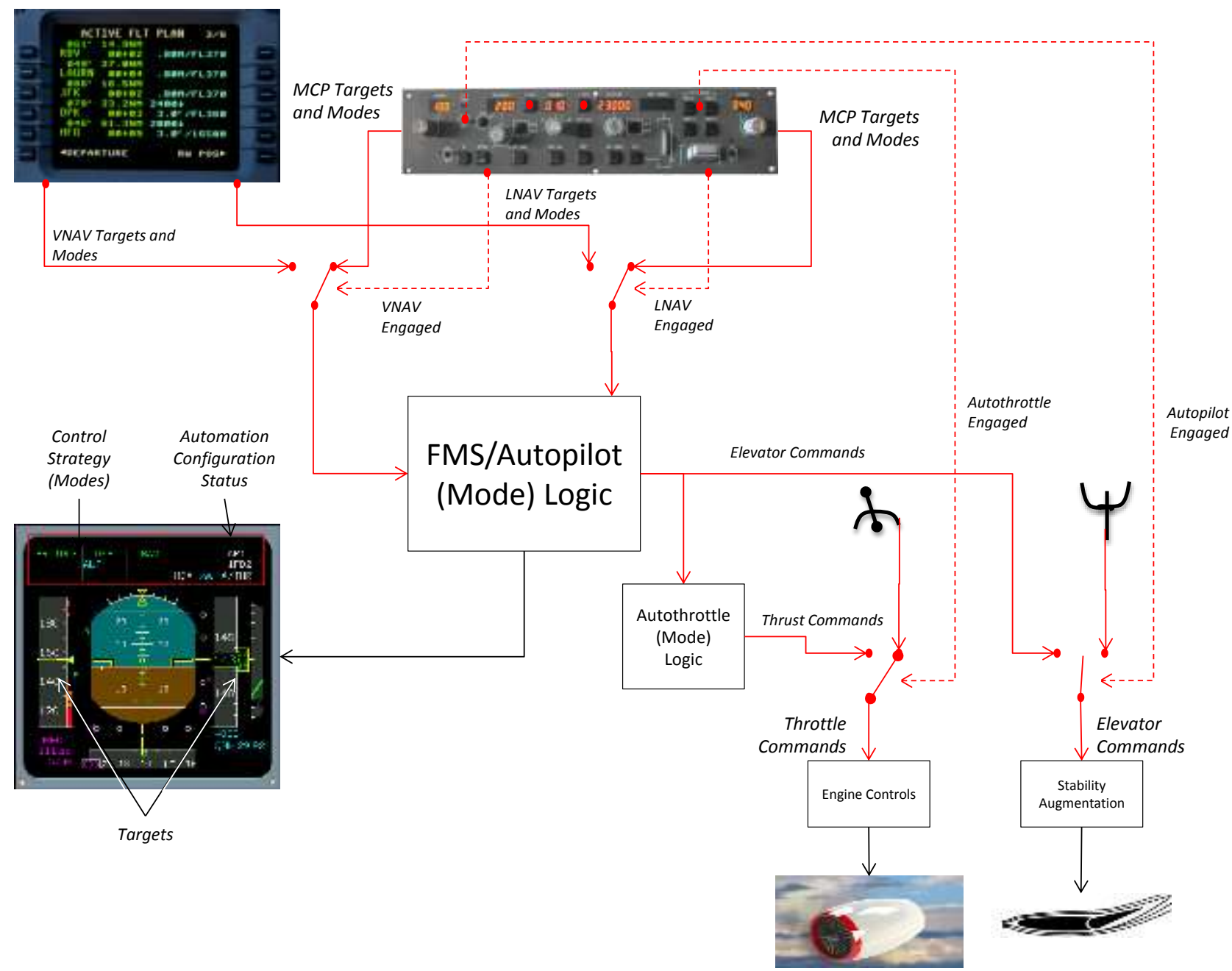

Figure 2: Automation Interfaces for Flight Plan Entry, Target/Mode Selection, and Manual Control Using the Four Switches LNAV, VNAV, A/P, and A/T. 
may use the MCDU to change the flight plan programmed into the FMC and VNAV and LNAV will remain engaged. If the new procedure cannot be performed by amending the flight plan (or the flight crew determines that reprogramming the FMC would be too difficult or time consuming), then VNAV and/or LNAV are disengaged, and the procedure is conducted by flight crew selection of targets and modes on the MCP. If the flight plan programmed into the FMC cannot be easily amended and the trajectory cannot be easily achieved in a timely fashion through selection of control strategies (i.e. modes) and targets on the MCP, the $\mathrm{A} / \mathrm{P}$ and/or $\mathrm{A} / \mathrm{T}$ will be disengaged and manual control exerted.

This automation architecture enables combinations of engagement status. For example, LNAV can be engaged to provide automated FMC control to the lateral flight plan, while VNAV is not engaged enabling flight crew selection of altitude, airspeed and rate of climb/descent targets and control strategies. Another configuration may have LNAV and VNAV engaged with the A/P engaged and the $\mathrm{A} / \mathrm{T}$ not engaged. In this way the flight crew would be manually adjusting thrust as both lateral and vertical trajectories are commanded by the automation to follow the flight plan.

All told there are twelve (12) combinations of LNAV, VNAV, A/P and A/T engagement status that can be selected by the flight crew when the automation is controlling at least one parameter.

As a consequence, not only is the flight crew responsible for compliance with the flight plan by programming the FMC and/or selecting targets and control strategies, the flight crew must also configure the automation (using the $\mathrm{A} / \mathrm{P}, \mathrm{A} / \mathrm{T}, \mathrm{LNAV}$ and VNAV switches) to ensure that the appropriate targets are used.

\section{Analysis of CFIS Accidents}

Twenty-two CFIS accidents and incidents were analyzed [1]. These accidents and incidents were characterized by a structurally, mechanically, and electronically sound commercial airliner decelerating through the minimum safe operating speed $\left(1.3 \mathrm{~V}_{\text {Stall }}\right)$ to the stick-shaker stall speed. These accidents, follow a pattern: a triggering event (e.g., sensor failure, flight crew entry) resulted in a mode change or change in automation engagement status, that led to an inappropriate command, that in turn resulted in the speed envelope violation.

In each of these accidents, the flight crew was not able to intervene in a timely manner. In all of these cases, the aircraft trajectory (e.g., inappropriate deceleration) associated with the inappropriate automation commands could not be detected or recognized as it was masked by an appropriate trajectory leading up to the speed envelope violation. Further, the cues identifying the triggering events and their effect on automation modes and engagement status did not lead to detection, recognition, or diagnosis as they were hidden from the flight crew by the absence of explicit annunciation (i.e. required inference using memorized rules for interpreting data on the display), or used overloaded mode labels.

A further detailed analysis of a subset of the CFIS accidents not related to changes in aerodynamic properties of the aircraft (e.g. icing) and errors in computation of the aircraft speed envelope, revealed that these accidents were characterized by a situation in which the automation was no longer actively controlling to the airspeed target.

There were two effects of the triggering events on the automation that yielded this condition (Table 1): 1) the automation was engaged, but transitioned to a mode that does not control to the speed target, or 2) the automation was no longer engaged for speed control.

\section{Automation Engaged, but no Active Speed Control (Inappropriate Mode)}

In several accidents, the effect on the automation of the triggering events was to cause a transition to a control mode combination that did not directly control airspeed. The Turkish Airlines (TA) 1951 accident is an example of this phenomenon (see Table 1). The aircraft was vectored for an instrument approach that resulted in a late localizer capture and subsequent clearance to descend that left the aircraft fast and above the glideslope.

After receiving a clearance to land, the flight crew instructed the automation to descend to recapture the glideslope from above and to decelerate to the landing speed. At this time, a latent failure of the Radio Altimeter (RA) sensor on the Captain's side caused the RA to read -8 ' when the aircraft was 
Table 1: CFIS Accidents When the Automation Was No Longer Actively Controlling Airspeed

\begin{tabular}{|l|l|}
\hline $\begin{array}{c}\text { Effects of } \\
\text { Triggering Events } \\
\text { on Automation }\end{array}$ & \multicolumn{1}{|c|}{ Accidents and Incidents } \\
\hline $\begin{array}{l}\text { Automation } \\
\text { engaged, but no } \\
\text { active speed } \\
\text { control }\end{array}$ & $\begin{array}{l}\text { OZ 214 (dormant mode) } \\
\text { TA 1951 (fixed thrust mode) }\end{array}$ \\
\hline $\begin{array}{l}\text { Automation no } \\
\text { longer engaged for } \\
\text { speed control }\end{array}$ & $\begin{array}{l}\text { AAL 903 } \\
\text { ThomsonFly } \\
\text { Bournemouth } \\
\text { ThompsonFly Belfast } \\
\text { ThomsonFly, no } \\
\text { location specified } \\
\text { Provincial Airlines } \\
\text { Midwest 490 } \\
\text { Air France 447 }\end{array}$ \\
\hline
\end{tabular}

at 2000'. Due to the erroneous sensor data, the automation incorrectly determined that the aircraft had landed and required a flare maneuver; this caused the Autothrottle to transition to the Landing Flare mode. In this mode the throttles are locked at the idle position and do not control airspeed. In this configuration, the aircraft decelerated well below the minimum safe operating speed $\left(1.3 \mathrm{~V}_{\text {Stall }}\right)$.

In the Asiana Air 214 (OZ 214) accident, the flight was vectored for visual approach at $14 \mathrm{~nm}$ to the runway at an altitude that left the aircraft above the desired three-degree glideslope. At $5 \mathrm{~nm}$ to the runway, the aircraft remained well above the desired glide path. In an attempt to increase the airplane's descent rate and capture the desired glide path, the flight crew selected an autopilot mode (flight level change speed [FLCH SPD]) that instead resulted in the autoflight system initiating a climb because the airplane was below the previously selected Go Around altitude. The flight crew disconnected the $\mathrm{A} / \mathrm{P}$ and moved the thrust levers to idle. This action signaled the $\mathrm{A} / \mathrm{T}$ to transition to a dormant mode in which the A/T does not directly control airspeed, but allows the flight crew to manually adjust the flight trajectory by setting the thrust. In this configuration, the aircraft decelerated well below the minimum safe operating speed $\left(1.3 \mathrm{~V}_{\text {Stall }}\right)$.

\section{Automation Not Engaged}

In several other accidents, the automation autonomously disengaged, no longer coupling the automation commands to the control surfaces and engines. American Airlines (AAL 903) is an example of this scenario. AAL 903 was instructed to hold at 16,000 ' due to a weather cell on the arrival procedure. The aircraft decelerated and leveled-off as it made the turn into the holding pattern. During this period, with the A/T commanding idle thrust, the A/T disengaged. Without the A/T coupled to the engines, and the thrust at idle, the aircraft decelerated well below the minimum safe operating speed $\left(1.3 \mathrm{~V}_{\text {Stall }}\right)$.

\section{Analysis of Human-Computer Interaction}

To intervene in these scenarios, the flight crew must detect, recognize and diagnose the situation.

On the flight deck, the primary source of information on engagement status, target, mode, and aircraft energy-state is the Primary Flight Display (PFD). The modern "glass" PFD is an integrated version of the federated "steam gauge" displays that had one gauge for each parameter. Many of the features of the PFD were designed prior to the evolution of the automation and were not explicitly designed to support the new tasks required to operate highly automated aircraft.

The PFD (Figure 3) is organized as follows. The center section of the display is an attitude indicator (AI). The top of the AI has a bank indicator. To the left of the AI is an airspeed tape. To the right of the $\mathrm{AI}$ are altitude and vertical speed tapes. Below the AI is a partial compass rose for heading display. Above the AI is a Flight Mode Annunciator (FMA).

The tapes display the actual airspeed, altitude, and vertical speed along with their associated targets. In addition, the airspeed tape displays information on the speed envelope. "Barber poles" --striped bars -indicate regions outside of the safe energy-state for the aircraft. On the low end of the speed envelope, the safe operating speed is set $30 \%$ above the stall speed, creating a buffer zone. The $1.3 \mathrm{~V}_{\text {Stall }}$ zone is represented using a yellow barber pole. The unsafe $\mathrm{V}_{\text {Stall }}$ is represented using a red barber pole. 


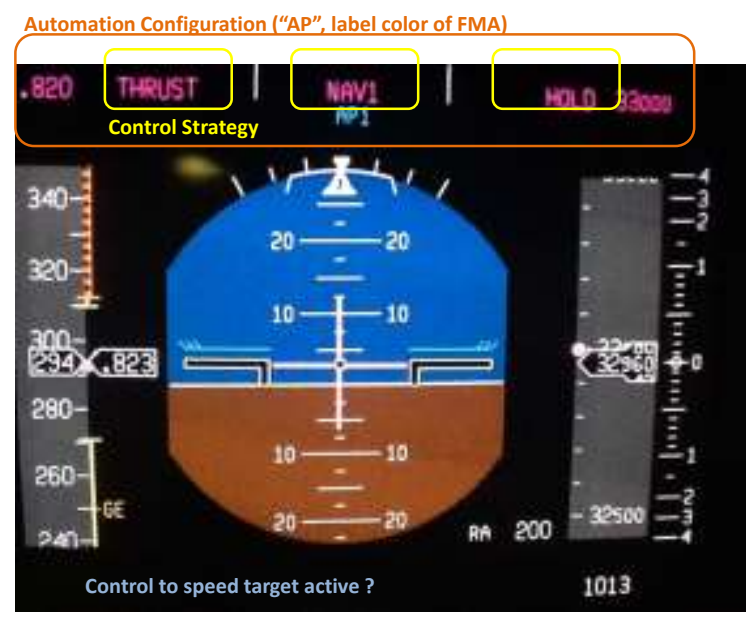

Figure 3: Primary Flight Display (PFD) Displays Information that is an Integrated Form of Formerly Federated Gauges.

The numerical altitude and speed targets are shown above the tapes. When the target is within the scaling of the tape, it is shown on the tape with a target icon. The values indicating the present state of the aircraft are centered on the airspeed and altitude tapes. When the present state is at the target, the target icon overlaps with the present state value.

To avoid CFIS using the traditional PFD, the pilot must obtain data from a variety of sources, integrate the data into a coherent whole, and rely on memorized rules to extract meaning from the result. The information required to detect, recognize and diagnose the two scenarios described above is distributed across the PFD. To diagnose a CFIS scenario, the pilots must determine:

1) is airspeed control active?

If airspeed control is not active, the pilots must then determine why not:

2) what is the control strategy (i.e. mode) of the airspeed?

3) what is automation configuration?

\section{Is Airspeed Control Active?}

The PFD does not explicitly address this question. The aircraft automation can control airspeed by pitch using the autopilot or by thrust using the Autothrottle. To determine whether the $\mathrm{A} / \mathrm{P}$ and/or $\mathrm{A} / \mathrm{T}$ are engaged, the pilot must read the
FMA. Typically, when the A/P or A/T is engaged, the corresponding mode annunciation on the FMA will be displayed in green. When the $\mathrm{A} / \mathrm{P}$ or $\mathrm{A} / \mathrm{T}$ is engaged, some FMA's will also display " $\mathrm{A} / \mathrm{P}$ " and/or " $\mathrm{A} / \mathrm{T}$ " in green. If the $\mathrm{A} / \mathrm{P}$ or $\mathrm{A} / \mathrm{T}$ is armed or engaged, the respective buttons on the MCP may be lit. $^{1}$

However, the automation may be engaged but engaged in a mode that does not control to the displayed target. For example, in the Asiana accident the $\mathrm{A} / \mathrm{T}$ was engaged in the "HOLD" mode that indicates that the $\mathrm{A} / \mathrm{T}$ is "on hold" waiting for instructions while the pilot is exerting manual control. Furthermore, the speed target is displayed on the PFD but not controlled. There is no single display component that reliably indicates to the pilot whether airspeed is or is not being controlled. In this example, the pilot must recall from memory that airspeed is not being controlled when the $\mathrm{A} / \mathrm{T}$ is engaged in the "HOLD" mode despite the other cues that suggest that airspeed is being controlled.

\section{What is the Control Strategy (i.e. mode)?}

The mode selected is displayed on the FMA. The center FMA label identifies the mode selected to control the lateral path (i.e. course, heading, VOR, localizer). The left and right labels identify the modes controlling the vertical axis. There are two designs for the labels. One design indicates which control surface is controlling speed or altitude. For example, speed can be controlled by PITCH or by THRUST. The other design indicates what parameter is controlled by the thrust and pitch. For example, pitch can control SPEED, ALTITUDE, Vertical Speed (VS), or PATH. The labeling of the modes and exclusive use of labels for each mode is critical to recognition and interpretation of the mode.

\section{What is the Automation Configuration?}

The engagement status of the $\mathrm{A} / \mathrm{P}$ and $\mathrm{A} / \mathrm{T}$ is located under the FMA. This information is also duplicated on the MCP by backlit push buttons.

\footnotetext{
${ }^{1}$ When the $\mathrm{A} / \mathrm{P}$ or $\mathrm{A} / \mathrm{T}$ disengage, an aural alert is generated and the Altitude|Heading or Speed labels are briefly surrounded by rectangles (not shown in Figure 3).
} 
When the $\mathrm{A} / \mathrm{P}$ and $\mathrm{A} / \mathrm{T}$ disengage, the Altitude|Heading and Speed labels are surrounded by an A/P OFF rectangle, or an A/T OFF rectangle (not shown in Figure 4).

The information required to detect, recognize and diagnose the two scenarios described above is distributed across the PFD (Table 2).

Table 2: Summary of Location on PFD for Information Required to Detect, Recognize, and Diagnose CFIS Scenarios.

\begin{tabular}{|l|l|l|}
\hline \multicolumn{1}{|c|}{ Information } & \multicolumn{1}{|c|}{$\begin{array}{c}\text { Location on } \\
\text { Traditional PFD }\end{array}$} & $\begin{array}{l}\text { Memorized Rules } \\
\text { to Interpret }\end{array}$ \\
\hline Control active & FMA & $\begin{array}{l}\text { Label interpretation } \\
\text { Location of A/P and } \\
\text { A/T labels and } \\
\text { presence/absence of } \\
\text { A/P and A/T Label. } \\
\text { Color of FMA and } \\
\text { Targets }\end{array}$ \\
\hline Engagement Status & Below FMA for A/P & $\begin{array}{l}\text { Location of A/P and } \\
\text { A/T labels and } \\
\text { presence/absence of } \\
\text { A/P and A/T Label. } \\
\text { Color of FMA and } \\
\text { Targets }\end{array}$ \\
& FMA and Targets for \\
& VNAV and LNAV & Label interpretation \\
\hline Mode selected & FMA & \\
\hline & & None \\
\hline Target selected & Tape & None \\
\hline Actual & Tape & \\
\hline
\end{tabular}

In addition to issues with interpreting FMA, Mumaw et. al. [7] discovered through eye-tracking that flight crews do not inspect the FMA (typical fixation time is less than 5\%), nor do the flight crews value the FMA information [8]. The Mumaw study showed that $53 \%$ of pilots inspected the FMA within 10 seconds of manually induced transitions, $45 \%$ following expected automation-induced transitions (e.g. capture altitude), and $62 \%$ after an unexpected of automation-induced transitions.

\section{Requirements for a CFIS Intervention Display}

To support the flight crew CFIS intervention task, the flight deck user-interface shall enable the flight crew to detect, recognize, and diagnose the CFIS scenario prior to the speed deviation. The display shall explicitly convey answers to the following questions in a salient and unambiguous manner, without the need for memorized rules:

(1) Is airspeed control active?

(2) Is the automation coupled?

(3) What device (elevators/pitch or engines/thrust) is controlling airspeed?

(4) To what target is airspeed being controlled?

\section{Example Design: Integrated Airspeed Tape}

The integrated airspeed tape display proposed here would provide answers to these questions in one location without requiring the use of memorized rules. The following description provides a conceptual treatment of the display. The ergonomics of the symbology, color schemes, etc. have not been addressed. Further, there are several details that are not provided in this description.

The integrated airspeed tape display has three graphic icons whose shapes and colors are manipulated: (1) actual airspeed, (2) numerical airspeed target, and (3) target pointer. The target pointer slides with the tape as the airspeed changes when it is within the range of the tape display. When the target is not within the range of the display it is parked at the top or bottom of the tape.

The actual airspeed icon indicates the device that is controlling airspeed. When the engines are controlling airspeed, the actual airspeed is marked with an engine icon. When the elevator is being used to control speed, the actual airspeed is marked with an elevator icon.

The source of the targets is defined by the color. For example, magenta could reflect targets from the flight plan whereas white could reflect targets from the MCP. The icons for both the actual values and targets could use the color scheme. Information identifying active speed control is shown on the numerical targets and target pointer. When speed control is not active, large crosses are displayed over both the numerical target and target pointer displays.

Thus, at a single glance the pilot can determine answers to all four of the questions above (Figure 4). 
Figure 4a illustrates a climb with speed controlled via the elevators and maximum thrust providing altitude. Figure $4 \mathrm{~b}$ illustrates a level flight with speed controlled via the engines and altitude via the elevators. The concept of icons on the tapes can be found in [9].

The engine and elevator icon can also be used to identify the type of control. Max thrust is shown with a bolded engine icon (Figure 4a), idle thrust with a thin line icon, and speed on throttle with a filled-in icon (Figure 4b). The elevator icon should differentiate between airmass-referenced control (Figure 4a) and earth-referenced path control (e.g. ROC/D or path).
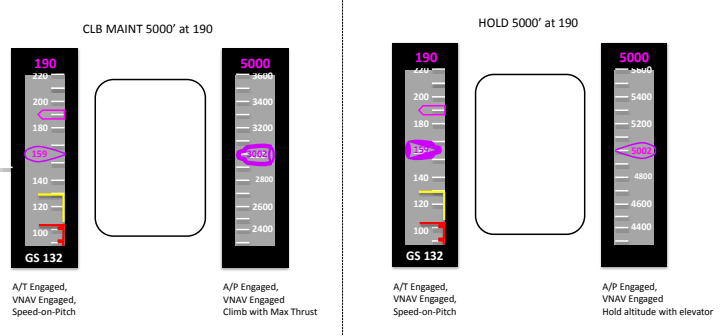

Figure 4: Control Strategy is Displayed by the Choice of Icons (Elevator or Engine) for Actual Airspeed and Altitude.

The configuration of the automation identifying the source of the targets is defined by the color. Magenta reflects targets from the flight plan. White reflects targets from the MCP. Both the icons for the actual values and targets use the color scheme. Figure 5 shows cases where VNAV is engaged and targets are derived from the flight plan.

Information identifying active speed control is shown on the numerical targets and target pointer. When speed control is not active the numerical target and target pointer display large crosses. When speed control is not active due to $\mathrm{A} / \mathrm{T}$ disengagement, the airspeed icon is a box (i.e. neither engine, or elevator) See Figure 5a. When speed control is not active due to mode selection while the $\mathrm{A} / \mathrm{T}$ is engaged, the airspeed icon is a dashed engine indicating a dormant mode (Figure 5d). When speed control is not active due to mode selection while the $\mathrm{A} / \mathrm{T}$ is engaged, the airspeed icon is or a locked engine indicating a locked throttle position (e.g. flare mode) (Figure 5e).
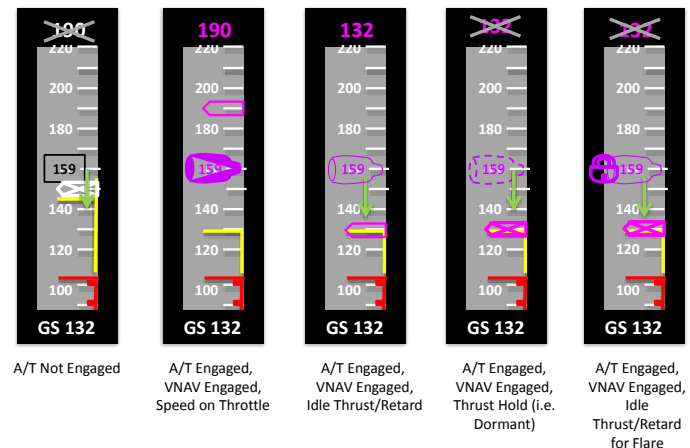

Figure 5: Example of an Integrated Airspeed Tape Designed for Intervention in CFIS Scenarios

The integrated airspeed tape introduces an icon on the tape to identify the control strategy (engine or elevator), whether speed control is active (shape of icon, shape of target icon, shape of target display), and automation configuration (shape and color of icon). These designs are summarized in Table 3.

Table 3: Example Design of an Integrated Airspeed Display for Intervention in the CFIS Scenario.

\begin{tabular}{|c|c|c|c|}
\hline Information & $\begin{array}{l}\text { Location on } \\
\text { Traditional } \\
\text { PFD }\end{array}$ & $\begin{array}{l}\text { Knowledge } \\
\text { Required to } \\
\text { Interpret } \\
\text { Traditional } \\
\text { PFD }\end{array}$ & $\begin{array}{c}\text { Integrated } \\
\text { Target } \\
\text { Display } \\
\text { (that } \\
\text { requires no } \\
\text { Interpretati } \\
\text { on) }\end{array}$ \\
\hline $\begin{array}{l}\text { Engagement } \\
\text { Status }\end{array}$ & $\begin{array}{l}\text { Below FMA for } \\
\text { A/P and A/T } \\
\text { FMA } \\
\text { Targets and } \\
\text { VNAV for } \\
\text { LNAV }\end{array}$ & $\begin{array}{l}\text { Location of } \\
\mathrm{A} / \mathrm{P} \text { and } \mathrm{A} / \mathrm{T} \\
\text { labels and } \\
\text { presence/abse } \\
\text { nce of } \mathrm{A} / \mathrm{P} \\
\text { and } \mathrm{A} / \mathrm{T} \\
\text { Label. } \\
\text { Color of FMA } \\
\text { and Targets }\end{array}$ & $\begin{array}{l}\text { Shape and } \\
\text { color of } \\
\text { airspeed icon }\end{array}$ \\
\hline $\begin{array}{l}\text { Mode } \\
\text { selected }\end{array}$ & FMA & $\begin{array}{l}\text { Label } \\
\text { interpretation }\end{array}$ & $\begin{array}{l}\text { Airspeed } \\
\text { icon (engine, } \\
\text { elevator) }\end{array}$ \\
\hline Control active & FMA & $\begin{array}{l}\text { Label } \\
\text { interpretation }\end{array}$ & $\begin{array}{l}\text { Shape and } \\
\text { color of } \\
\text { airspeed icon }\end{array}$ \\
\hline $\begin{array}{l}\text { Target } \\
\text { selected }\end{array}$ & Tape & None & $\begin{array}{l}\text { Shape and } \\
\text { icon } \\
\text { airspeed } \\
\text { target }\end{array}$ \\
\hline Actual & Tape & None & \\
\hline
\end{tabular}


The integrated airspeed tape display includes the Speed FMA, engagement status, as well as the target and actual airspeed. The FMA is displayed as a graphical icon for the actual airspeed. When the airspeed is controlled via thrust, the graphical icon is a jet engine. When the airspeed is controlled via pitch, the graphical icon is an elevator. Other icons and/or labels could also be used.

The jet engine icon would need to distinguish between maximum thrust, idle thrust, speed on thrust, and flare. In this example, the control strategies are captured boldness of the icon lines and internal shading. Idle thrust has thin lines and no shading. Maximum thrust has bold lines and complete shading. Speed control has a combination of shading and boldness of lines between maximum thrust and idle thrust. Flare is displayed with an engine icon at idle, with a lock icon. Other icons and/or labels could also be used.

When the $\mathrm{A} / \mathrm{T}$ is not engaged, no engine icon is displayed anywhere on the PFD. When VNAV is engaged and the $\mathrm{A} / \mathrm{T}$ and/or $\mathrm{A} / \mathrm{P}$ are engaged, the engine and elevator icons are magenta. When VNAV is not engaged and the $\mathrm{A} / \mathrm{T}$ and/or $\mathrm{A} / \mathrm{P}$ are engaged, the engine and elevator icons are magenta. Other icons, colors, and/or labels could also be used.

\section{Conclusions}

This paper describes the results of an analysis of CFIS events and the associated Human-Computer Interaction for the flight crew task of intervention in the CFIS scenarios. The analysis identified the CFIS events as the direct result of failure to actively control to the airspeed target. There were two causes: (1) automation not coupled, and (2) control strategy (mode) for speed control does not directly control airspeed.

The analysis of the flight deck cues needed for the flight crew to detect, recognize and diagnose these scenarios revealed that the data needed to determine if airspeed control to the target is active is not explicitly annunciated. Further, the information required to diagnose the causes is located in different locations on the PFD, and memorized rules are required to interpret these data. In this way, the PFD is not designed to explicitly support this task.
The requirements for a flight deck display to support the CFIS intervention task without memorized rules are described. An example of a new airspeed tape design meeting these requirements is presented. The proposed design explicitly identifies whether speed control is active, the control strategy (mode), and the automation configuration.

\section{Problem of Evolving Functionality without Evolving Displays}

The modern "glass" PFD is an integrated version of the federated "steam gauge" displays. Data on the gauges for airspeed, horizontal situation, bank, altitude, rate-of-climb/descent, and heading were consolidated onto a single digital display. This was supplemented by adding flight mode annunciation, localizer and glideslope deviation displays, tuned navaids, and radio altimeter information. In this way the PFD supported the flight crew tasks that were performed by the steam gauges and other federated displays.

Many of the features of the PFD were designed prior to the evolution of the automation and may not have been explicitly designed to support new tasks required by the automation. One of these new tasks is the monitoring of automation. The PFD was not designed to answer the question is the airspeed target being actively controlled? And if not, why not (coupling, non-speed control mode)?

\section{Certification}

Equipment certification tests may include the following checks of intended function and displays:

\section{Intended Functions}

(1) Can the new function affect sensors or flight crew entries that directly or indirectly results in automation mode selection that does not actively control aircraft trajectory resulting in any of the following hazards: loss of safe energy-state, collision with terrain or obstacles, or collision with traffic?

(2) Does the new function include modes that control aircraft trajectory?

(3) If yes, do any of these modes (or mode combinations) result in a situation where 
energy-state, lateral trajectory, or vertical trajectory is not actively controlled?

(4) If yes, can it be shown that the finite set of combinations of conditions do not result in a situation where energy-state, lateral trajectory, or vertical trajectory is not actively controlled?

\section{Displays}

(1) Do the displays explicitly annunciate an automation mode selection that does not actively control aircraft trajectory resulting in any of the following hazards: loss of safe energy-state, collision with terrain or obstacles, or collision with traffic?

(2) Do the displays explicitly annunciate the causes of not actively control aircraft trajectory (coupling, mode, target, command) resulting in any of the following hazards: loss of safe energy-state, collision with terrain or obstacles, or collision with traffic?

\section{Confusion Regarding "Mode Confusion"}

Researchers have discussed the notion of "mode confusion." This generally refers to confusion of the flight crew described as "What is the automation doing now?" Why is it doing that?" and "What will the automation do next?" [10], [11]. Mode complexity is widely blamed for as the culprit [12], [13], [14].

This analysis suggests that the number or complexity of modes is not the root cause of the CFIS phenomenon that is associated with the flight crew task of managing unexpected, unplanned flight plan deviations. The analysis shows that the automation configuration (i.e. coupling of $\mathrm{A} / \mathrm{P}$ and $\mathrm{A} / \mathrm{T}$ ) is a critical component of automation design and is not compatible with the three categories of tasks performed by the flight crew.

\section{References}

[1] Sherry, L.., R. Mauro (2014) Controlled Flight into Stall (CFIS): Functional Complexity Failures and Automation Surprises. Integrated Communications Navigation and Surveillance (ICNS) Conference, April 8-10, 2014
[2] ARAC Recommendation (2013) ASHWG Draft Report - Low Airspeed Alerting Phase 2 Task (Retrofit Applications) - Revision A. Avionics System Harmonization Working Group (ASHWG). Tasking Notice 77 FR 11844 (March 3, 2011)

[3] Sherry, L.., R. Mauro (2014) Thrust Advance Indicator. CATSR Internal Report 2014-001. catsr.vse.gmu.edu/pubs

[4] Williams, D.H. R. M. Oseguera-Lohr, and E. T. Lewis (2011) Energy Navigation: Simulation Evaluation and Benefit Analysis. Langley Research Center, Hampton, Virginia. NASA/TP-2011-217167

[5] Kineshige, J.T., S. Shivanjli L. Martin, S. Lozito, V. Dulchinos, (2014) Flight-Deck Strategies and Outcomes When Flying ScheduleMatching Descents. AIAA Guidance, Navigation, and Control Conference; 19-22 Aug. 2013; Boston, MA; United States[6] Adam, G., J. Condette (2013) Study on Aeroplane State Awareness during Go-Around. Bureau d'Enquetes et d' Analyses pour a securite de l'aviation civile. Zone Sud - 2000 Rue d'paris, Aeroport du Bourget, 93352 L Bourget, Cedex, France.

[7] Mumaw, R.J., Sarter, N.B., and Wickens, C.D. (2001): Analysis of Pilots' Monitoring and Performance on an Automated Flight Deck. 11th International Symposium in Aviation Psychology. Columbus: Ohio State University.

[8] Huettig, G., Anders G., and Tautz, A. (1999): Mode Awareness in a modern glass cockpit attention allocation to mode information. In Jensen R. (Eds): Proceedings of the 1999 Ohio State University Aviation Psychology Conference. Dayton, OH: Ohio State University.

[9] Hutchins, E. (1996) The Integrated Mode Management Interface. NASA CR 022200. NASA Ames Research Center. Moffet Field, CA.

[10] Wiener, E., D.C. Nagel (1988) Human Factors in Aviation. Academic Press, London.

[11] Sarter, N. and Woods, D. D. (1995): How in the World Did We Ever Get into That Mode? Mode Error and Awareness in Supervisory Control. Human Factors 37(1), 5-19. 
[12] McGreevy, M.W. (1996) Reporter Concerns in 300 Mode-Related Incident Reports from NASA's Aviation Safety Reporting System. NASA Technical Memorandum 110413. NASA Ames Research Center. Moffet Field, CA.

[13] Commercial Aviation Safety Team (2000) Final Report of the Loss of Control JSAT: Results and Analysis, Paul Russell and Jay Pardee, Cochairs, December 15,2000.

[14] Woods, D. D. and Sarter N. B. (2000): Learning from Automation Surprises and Going Sour Accidents. In Sarter N. B. and Amalberti R. (Eds): Cognitive Engineering in the Aviation Domain. Lawrence Erlbaum Associates, Mahwah, New Jersey.

\section{Acknowledgements}

Technical contributions by Immanuel Barshi, Michael Feary, Steve Jacklin, Randall Bailey, Steve Young, Paul Krasa (NASA), Bill Bramble (NTSB),
Bob Matthews (retired FAA), Karl Fennell (United Airlines), Marty Alkin (FedEx), Jim DeArmon (Mirre-CAASD), George Donohue, John Shortle, Anvardh Nanduri, Kevin Lai (George Mason University). This research was funded by NRA NNX12AP14A.

\section{Email Addresses}

1sherry@gmu.edu

mauro@uoregon.edu

33rd Digital Avionics Systems Conference

October 5-9, 2014 